\title{
Abnormal morphology in Amblyomma coelebs and Amblyomma cf. oblongoguttatum (Acari: Ixodidae) collected on free-roaming Central American Tapir (Tapirus bairdii) from Nicaragua
}

\author{
Lillian DOMÍNGUEZ1,3 (D), Jeffrey ARANA-ESPINOZA² (i), Sergio BERMÚDEZ CASTILLER01,3 (i) \\ ${ }^{1}$ Department of Research in Medical Entomology, Gorgas Memorial Institute for Health Research, Panama \\ 2 Tapir Nicaragua Project, Bluefield, Nicaragua \\ ${ }^{3}$ Corresponding authors: ldominguez@gorgas.gob.pa; sbermudez@gorgas.gob.pa
}

Received: 2 September 2021

Accepted: 11 November 2021

Available online: 27 January 2022

ABSTRACT: In this work we describe abnormalities in Amblyomma coelebs and Amblyomma cf. oblongoguttatum adults collected from Tapirus bairdii. The observed anomalies in adults corresponded to general (asymmetry of scutum and idiosoma), and local malformation (atrophy and ectromely). This is the first record of morphological anomalies in $A$. coelebs and also it increases the observations of malformations in ticks from Nicaragua and Central America.

Keywords: Ixodidae, Amblyomma, abnormalities, Nicaragua.

Zoobank: http://zoobank.org/F1DBDB9B-07A4-4F1A-8F38-27041752FD19

Ixodidae comprise 760 species of hard ticks, which are studied for their relevance in public health (Guglielmone and Robbins, 2018; Guglielmone et al., 2021). However, other aspects related to its biology may go unnoticed or be less well known. One of these aspects is the malformations or abnormalities in its morphology, phenomena that have been reported in the genera Amblyomma, Dermacentor, Haemaphysalis, Hyalomma, Ixodes and Rhipicephalus (Kar et al., 2015). Abnormalities in the idiosoma are considering as rare and can be observed in any stage (Nuttal, 1914; Guglielmone et al., 1999; Keskin, 2018). In recent years, these phenomena have been reported increasingly, and effort has been made to understand the origin of these malformations, or to assess whether they affect the ability of these ticks to feed and transmit pathogens (Nuttal, 1914; Kar et al., 2015; Keskin et al., 2016).

In Neotropical region, 137 species are known (Guglielmone et al., 2021), in 27 of which abnormalities have been reported (Domínguez et al., 2021). To the best of our knowledge in the genus Amblyomma close to 345 cases of malformations have been found in 20 species, specifically in $A$. auricularium, A. calcaratum, A. cajennense complex, A. dissimile, A. fuscum, A. mixtum, A. naponense, A. neumannii, A. oblongoguttatum, A. cf. oblongoguttatum, $A$. ovale, A. parkeri, A. parvitarsum, A. parvum, A. rotundatum, A. sabanerae, A. tapirellum, A. testudinis, A. tigrinum, and A. varium (Beaurepaire-Aragao, 1912; Joan, 1919; Brumpt, 1934; Fonseca, 1935; Aguirre et al., 1999; Guglielmone et al., 1999; Labruna et al., 2000, 2002, 2009; Muñoz-Leal et al., 2017; Rivera-Páez et al., 2017; DantasTorres et al., 2019; Domínguez and Bermúdez, 2020; Domínguez et al., 2020, 2021). In Central America, abnormalities in Ixodidae were reported from Panama, Costa Rica, and Nicaragua (Domínguez and Bermúdez, 2020; Domínguez et al., 2020, 2021).

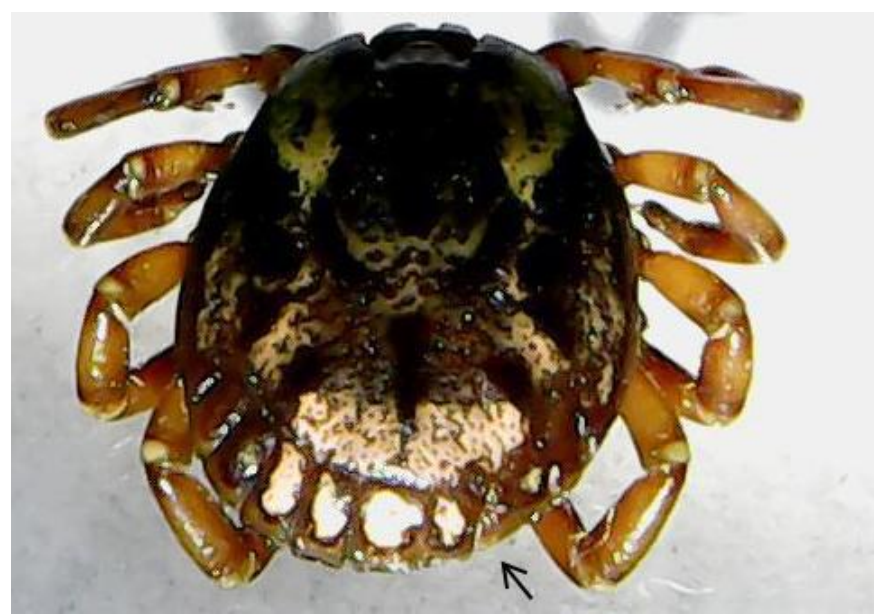

Figure 1. Dorsal view of festoon malformation in a $\mathrm{Am}$ blyomma coelebs male.

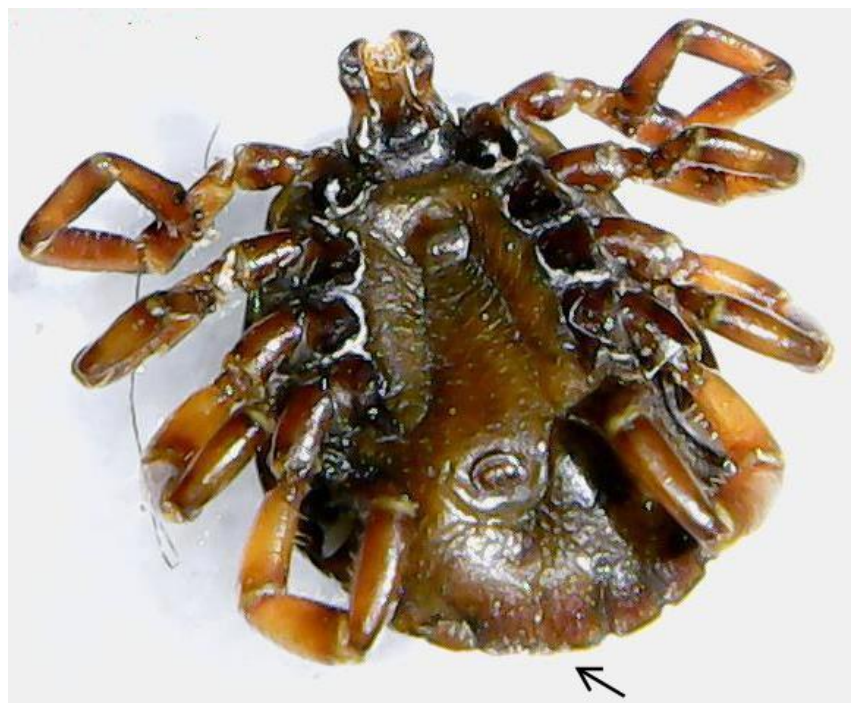

Figure 2. Ventral view of festoon malformation in a Amblyomma coelebs male. 


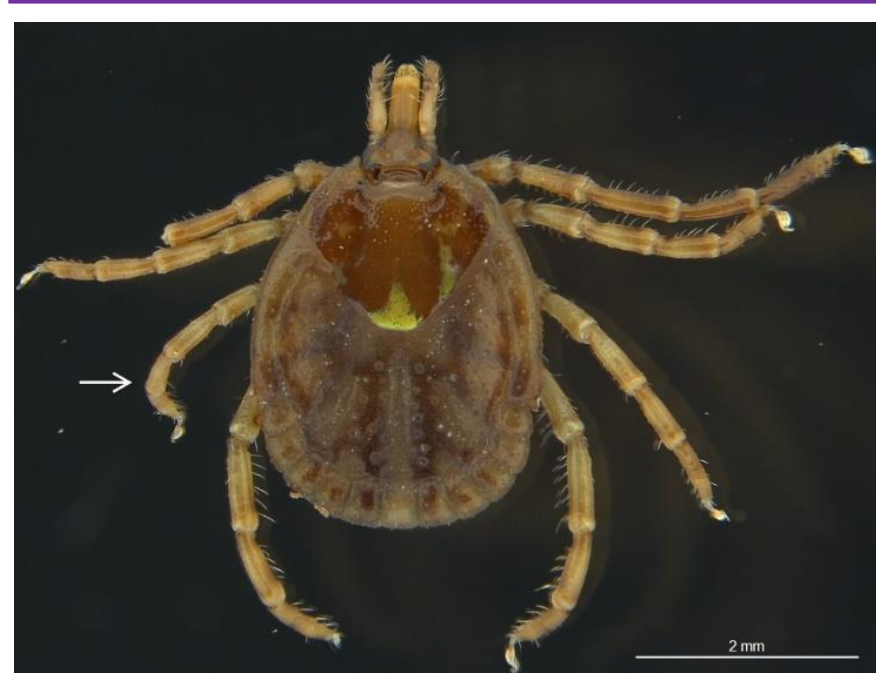

Figure 3. Dorsal view of Amblyomma cf. oblongoguttatum female with atrophy on the left 3 (arrow).

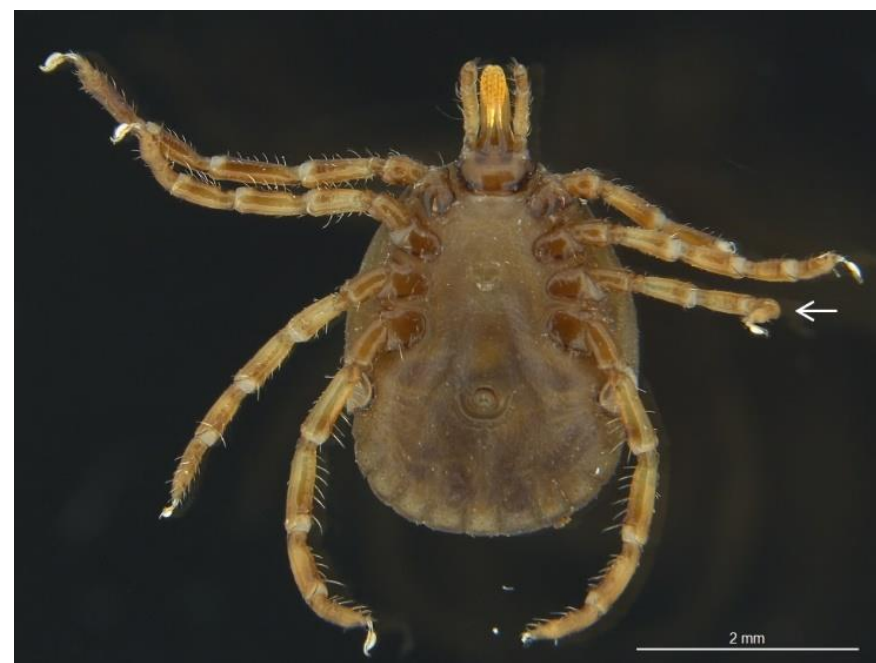

Figure 4. Ventral view of Amblyomma cf. oblongoguttatum female with atrophy on the left 3 (arrow).

In this study we report the abnormalities in two species of Amblyomma from Nicaragua collected from wild tapirs. Earlier, Arana et al. (2021) collected 91 ticks from seven tapirs (36 Amblyomma coelebs, 38 A. cf. oblongoguttatum, and 17 A. ovale). Abnormalities were observed in one $A$. coelebs male and three $A$. cf. oblongoguttatum females, and were classified according to Campana-Rouget (1959a,b). The photographs were taken using an Amscope SE306-A stereomicroscope and Amscope $2 \mathrm{mp}$ MD200 USB digital camera (Figs 1 and 2), and a stereomicroscope (Leica M205 A) with digital camera (Leica MC170 HD) (Figs 3-8). The ticks were deposited in the Institute of Natural Resources Environment and Sustainable Development of the University of the Autonomous Regions of the Nicaraguan Caribbean Coast, Nicaragua, and in the Ectoparasites Collection of the "Dr. Eustorgio Méndez" Zoological Collection of the Gorgas Memorial Institute for Health Studies.

A male of $A$. coelebs had festoons abnormalities (Figs 1 and 2). This type of malformation is among the most common (Campana-Roget, 1959b). According to Campana-Roget (1959b) irregularities in the shape, and size of the festoons, and their reduction in their number by fusion and absence, may be due to the atrophy of the poste- rior part of the idiosoma. Irregular and fused festoons have been reported in Amblyomma marmoreum, bumps at the caudal tip in Rhipicephalus longiceps, partial absence of festoons in Rhipicephalus sanguineus s.l., and Haemaphysalis leachi (Campana-Roget, 1959a,b). In Neotropical ticks, these types of irregularities have been reported in species such as $A$. mixtum, $A$. cf. oblongoguttatum, and $A$. tapirellum (Nuttal, 1914; Domínguez et al., 2021).

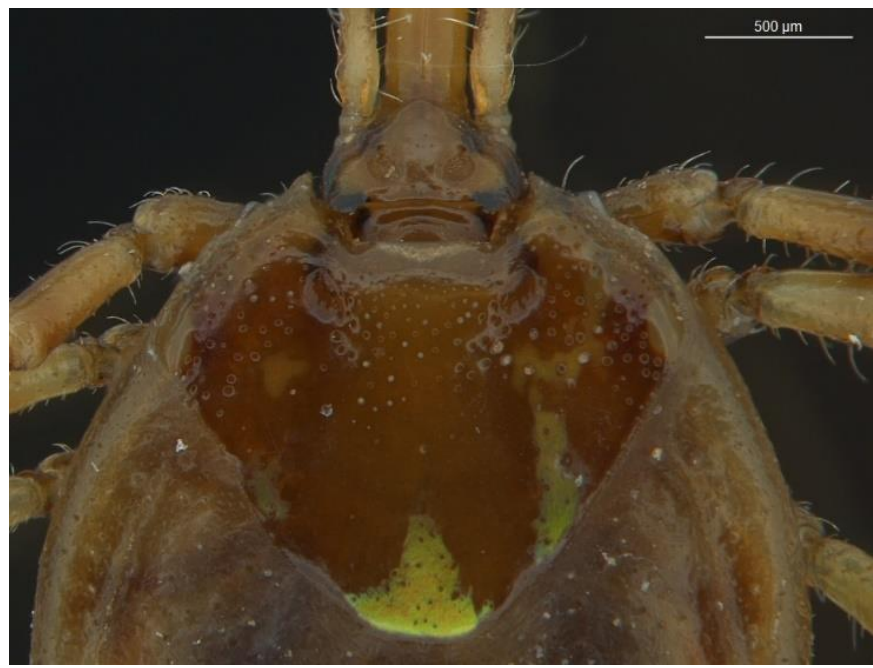

Figure 5. Asymmetry of the scutum of Amblyomma cf. oblongoguttatum female.

Regarding A. cf. oblongoguttatum, one female presented atrophy of the left leg 3 (Figs 3-5); while that another female exhibited ectromely of the left leg 4 (Figs 6-8). Idiosoma asymmetry is one of the anomalies that occurs most frequently in ticks and is often associated with other anomalies such as ectromely (loss of legs or leg segment) (Robison, 1920; Campana-Rouget, 1959a,b). According to these authors the aforementioned anomalies appear to be caused by uneven distension during the act of engorgement or may be related to an injury during the previous developmental stages. Other explanations indicate that abnormalities are probably the result of abnormal embryonic development, unfavorable molting conditions, and development under high humidity, injury, and abnormal regeneration of tick legs (Beaurepaire-Aragao, 1912; Robinson, 1920; Dergousoff and Chilton, 2007; Keskin et al., 2016).

In conclusion this work presents the first observation of abnormalities in $A$. coelebs by increasing the information of malformations to 30 tick species from Neotropical Regions, 17 of which from Central America and new reports for Nicaragua (Domínguez and Bermúdez, 2020; Domínguez et al., 2020, 2021).

\section{Authors' contributions}

Lillian Domínguez: Conceptualization (equal), data curation, visualization (equal), review and editing (lead). Jeffrey Arana-Espinoza: Methodology, resources, review and editing (supporting). Sergio Bermúdez Castillero: Conceptualization (equal), supervision, visualization (equal), writing - original draft. 


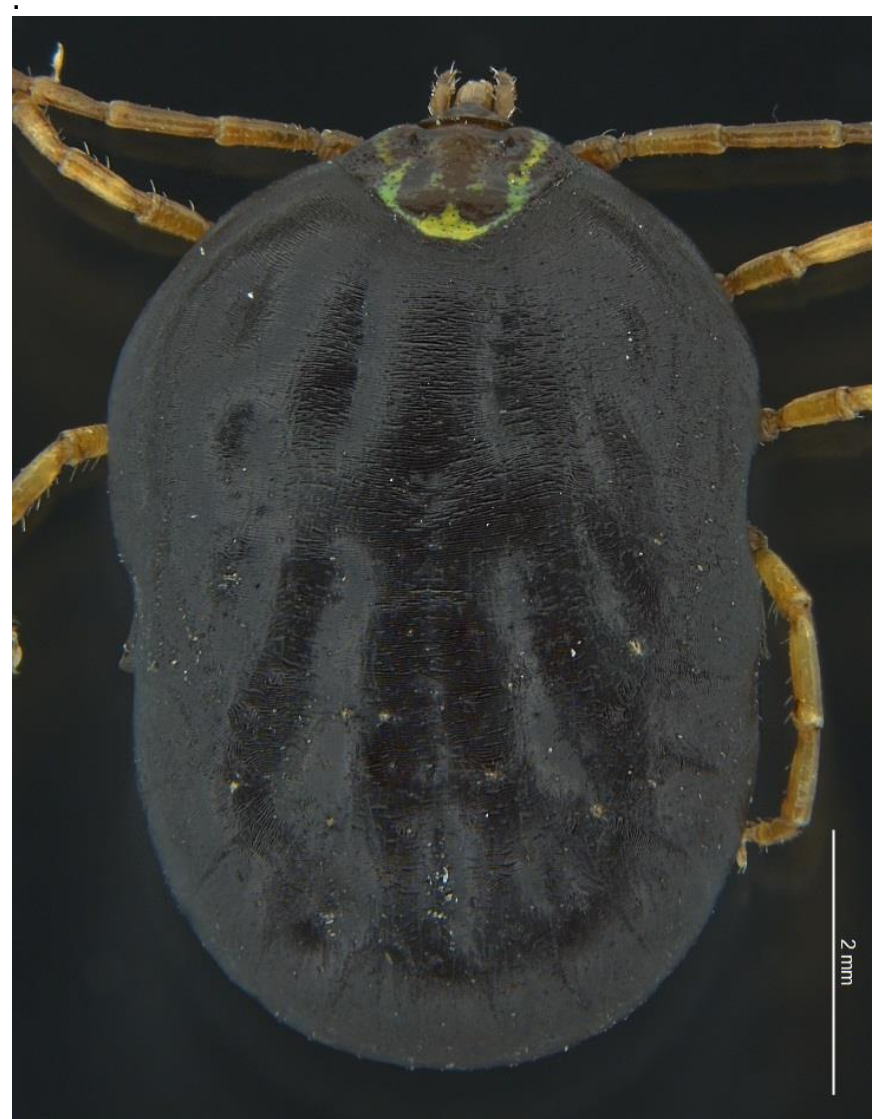

Figure 6. Dorsal view of Amblyomma cf. oblongoguttatum female with ectromely and asymmetry of idiosoma.

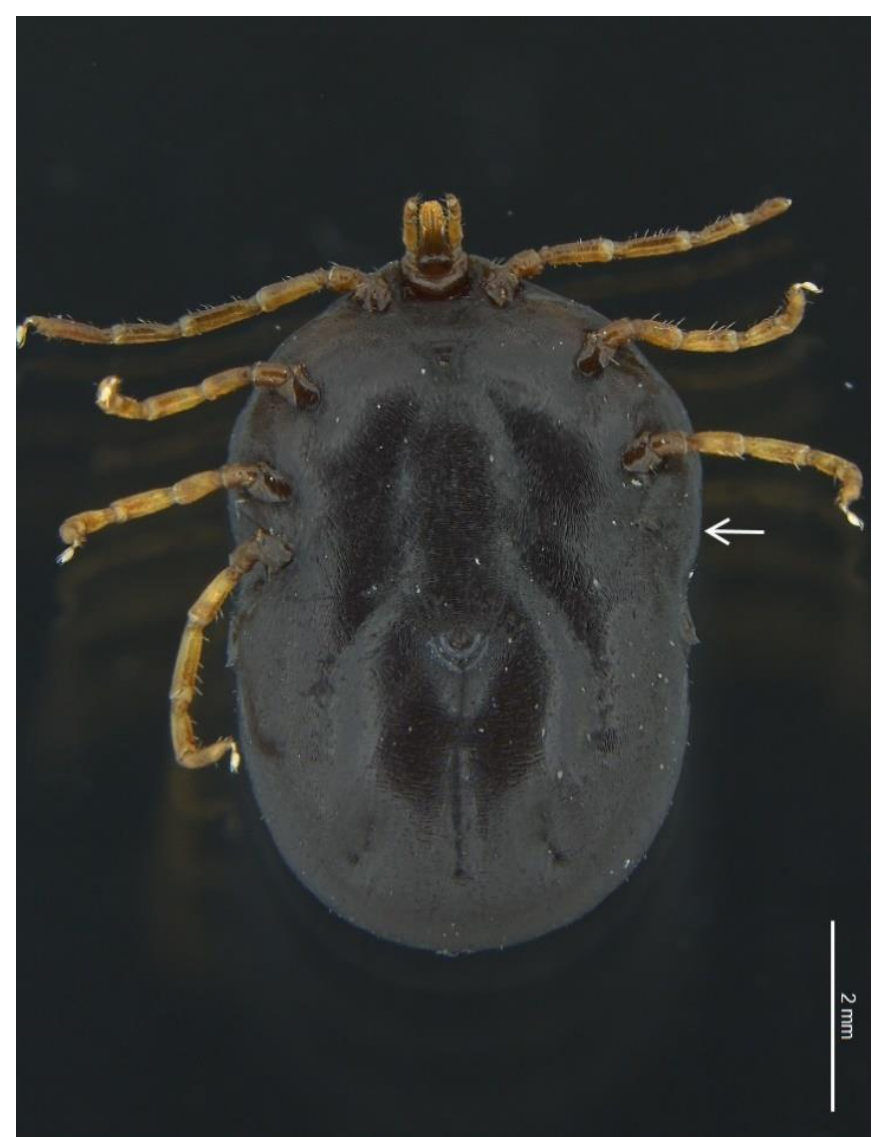

Figure 7. Ventral view of Amblyomma cf. oblongoguttatum female with ectromely (arrow) and asymmetry of idiosoma.

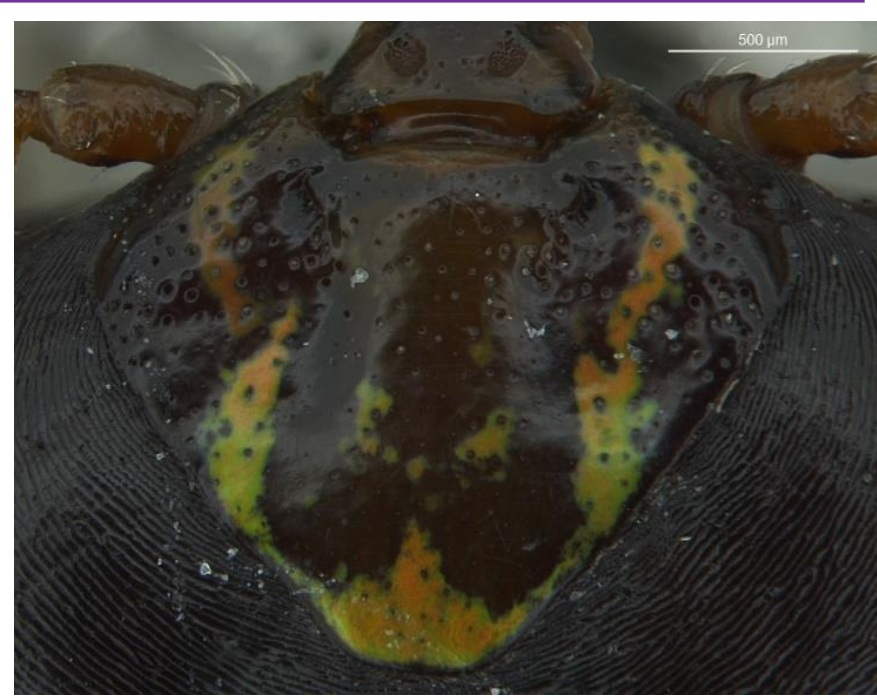

Figure 8. Asymmetry of the scutum of Amblyomma cf. oblongoguttatum female.

\section{Statement of ethics approval}

Not applicable.

Funding

Supported by Idea Wild.

\section{Conflict of interest}

The authors declare that they have no conflict of interest regarding this paper.

\section{REFERENCES}

Aguirre, D., Viñabal, A. and Guglielmone, A. 1999. The life cycle of Amblyomma neumanni Ribaga, 1902 (Acari: Ixodidae) in the laboratory. Experimental and Applied Acarology, 23: 159-164. doi: 10.1023/A:1006006711983

Arana, Y., Jordan, C., Dans, A., Martins, T. and Bermúdez, S. 2021. Ticks (Acari: Ixodidae) of Tapirus bairdii (Perissodactyla: Tapiridae) and notes on Amblyomma coelebs feeding on human, at Indio Maiz Biological Reserve, Nicaragua. Systematic and Applied Acarology, 26 (4): 829-834.

doi: $10.11158 /$ saa.26.4.13

Beaurepaire-Aragao, H. 1912. Contribuição para a sistematica e biolojia dos ixódidas: Partenojeneze em carrapatos: Amblyomma agamum n. sp. Memorias do Instituto Oswaldo Cruz, 4 (1): 96-119. [In Portuguese] doi: 10.1590/S0074-02761912000100007

Brumpt, E. 1934. Le gynandromorphisme chez les ixodinés. Un curieux cas obtenu dans un élevage d'Amblyomma dissimile. Annales de Parasitologie Humaine et Comparee, 12 (2): 98-104. [In French] doi: $10.1051 /$ parasite/1934122098

Campana-Rouget, Y. 1959a. La tératologie des tiques. Annales de Parasitologie Humaine et Comparee, 34: 209-260. [In French] doi: 10.1051/parasite/1959341209 
Campana-Rouget, Y. 1959b. La tératologie des tiques. Annales de Parasitologie Humaine et Comparee, 34: 354-431. [In French]

doi: $10.1051 /$ parasite/1959343354

Dantas-Torres, F., Fernandes Martins, T., Muñoz-Leal, S., Onofrio, V. and Barros-Battesti, D. 2019. Ticks (Ixodida: Argasidae, Ixodidae) of Brazil: Updated species checklist and taxonomic keys. Ticks Tick Borne Diseases, 10:101252.

doi: 10.1016/j.ttbdis.2019.06.012

Dergousoff, S. and Chilton, N. 2007. Abnormal morphology of an adult Rocky Mountain wood tick, Dermacentor andersoni (Acari: Ixodidae). Journal of Parasitology, 93: 708-709.

doi: 10.1645/GE-1073R.1

Domínguez, L. and Bermúdez, S. 2020. Firsts records of abnormalities and gynandromorphism in hard ticks (Ixodida: Ixodidae) from Panama. Systematic and Applied Acarology, 25 (7): 1199-1208.

doi: 10.11158/saa.25.7.4

Domínguez, L., Pérez, E., and Bermúdez, S. 2020. First report of abnormal morphology in the tick Dermacentor dissimilis (Acari: Ixodidae) and evidence of molt nymph-adult on hosts from Nicaragua. Acarological Studies, 2 (1): 46-50.

Domínguez, L., Montenegro, V. and Bermúdez, S. 2021. Morphologic abnormalities in Amblyomma mixtum, Amblyomma naponense, Amblyomma cf. oblongoguttatum and Amblyomma tapirellum (Acari: Ixodidae) of Costa Rica. Systematic and Applied Acarology, 26 (3): 509-518.

doi: $10.11158 /$ saa.26.3.1

Fonseca, F. 1935. Gymnandromorphismo em Amblyomma cajennense (Fabr., 1787). Memorias do Instituto $\mathrm{Bu}-$ tantan, 10: 39-41. [In Portuguese]

Guglielmone, A. and Robbins, R. 2018. Hard ticks (Acari: Ixodida: Ixodidae) parasitizing humans. A global review. Springer Nature, Cham, Switzerland, 313 pp. doi: 10.1007/978-3-319-95552-0

Guglielmone, A., Castella, A., Mangold, A., Estrada-Peña, A. and Viñabal, E. 1999. Phenotypic anomalies in a collection of Neotropical ticks (Ixodidae). Acarologia, 40: 127-132.

Guglielmone, A., Nava, S. and Robbins, R. 2021. Neotropical hard ticks (Acari: Ixodida: Ixodidae). A critical analysis of their taxonomy, distribution, and host relationships. Springer Nature, Cham, Switzerland, $486 \mathrm{pp}$. doi: 10.1007/978-3-030-72353-8

Guglielmone, A.A., Sánchez, M.E., Franco, L.G., Nava, S., Rueda, L.M. and Robbins, R.G. 2020. Valid Name List Ixodidae. Available

http://rafaela.inta.gob.ar/nombresgarrapatas/Listado
NombresValidos.aspx (Last accessed: 30 September 2021).

Joan, T. 1919. Caso de ginandromorfismo en una garrapata (Amblyomma neumanni Rib.). Actas 1er. Reunión Nacional Sociedad Argentina de Ciencias Naturales, Tucuman, Argentina, 421-425. [In Spanish]

Kar, S., Akyildiz, G., Yilmazer, N., Shaibi, T., Gargili, A. and Vatansever, Z. 2015. External morphological anomalies in ixodid ticks from Thrace, Turkey. Experimental and Applied Acarology, 67: 457-466.

doi: 10.1007/s10493-015-9948-6

Keskin, A., Simsek, E., Bursali, A. and Keskin, A. 2016. Morphological abnormalities in ticks (Acari: Ixodidae) feeding on humans in Central Black Sea region, Turkey. Zoomorphology, 135: 167-172.

doi: 10.1007/s00435-016-0306-y

Keskin, A. 2018. New teratological tick specimens (Acari: Ixodidae) from Turkey. Journal of Agriculture and Nature, 21 (1): 88-90.

doi: 10.18016/ksudobil.291077

Labruna, M., Homem, V., Heinemann, B. and Ferreira-Neto, J. 2000. A case of gynandromorphism in Amblyomma oblongoguttatum (Acari: Ixodidae). Journal of Medical Entomology, 37: 777-779.

doi: 10.1603/0022-2585-37.5.777

Labruna, M., Ribeiro, A., Cruz, M., Camargo, L. and Camargo, E. 2002. Gynandromorphism in Amblyomma cajennense and Rhipicephalus sanguineus (Acari: Ixodidae). Journal of Parasitology, 88: 810-811. doi: 10.1645/0022-3395(2002)088[0810:GIACAR]2.0.C0;2

Labruna, M., Onofrio, V., Beati, L., Arzua, M., Bertola, P., Ribeiro, A. and Barros-Battesti, D. 2009. Redescription of the female, description of the male and several new records of Amblyomma parkeri (Acari: Ixodidae), a South American tick species. Experimental and Applied Acarology, 49: 243-260.

doi: 10.1007/s10493-009-9257-z

Muñoz-Leal, S., Martins, T., Luna, L., Rodrigues, A. and Labruna, M. 2017. A new collection of Amblyomma parvitarsum (Acari: Ixodidae) in Peru, with description of a gynandromorphy and report of Rickettsia detection. Journal of Medical Entomology, 55 (2): 464-467. doi: 10.1093/jme/tjx194

Nuttal, G. 1914. Ticks abnormalities. Parasitology, 7: 250257. doi: 10.1017/S0031182000009677

Rivera-Paéz, F., Labruna, M., Martins, T., RodriguesSampieri, B. and Camargo-Matías, M. 2017. A case of gynandromorphism in Amblyomma mixtum (Acari, Ixodidae). Revista Colombiana de Entomología, 43 (2): 268-270. [In Spanish] doi: 10.25100/socolen.v43i2.5956 
Robinson, L. 1920. Malformations in ticks. Parasitology, 12: $175-179$.
Edited by: Salih Doğan

Reviewed by: Two anonymous referees

Citation: Domínguez, L., Arana-Espinoza, J. and Bermúdez Castillero, S. 2022. Abnormal morphology in Amblyomma coelebs and Amblyomma cf. oblongoguttatum (Acari: Ixodidae) collected on free-roaming Central American Tapir (Tapirus bairdii) from Nicaragua. Acarological Studies, 4 (1): 46-50. 